\title{
A New Variant of Mannosidosis with Increased Residual Enzymatic Activity and Mild Clinical Manifestation
}

\author{
GIDEON BACH, ${ }^{23}$ GERTRUDE KOHN, ELI E. LASCH, M. EL MASSRI, ASHER ORNOY, ELIEZER \\ SEKELES, CYRIL LEGUM, AND MAIMON M. COHEN \\ Department of Human Genetics, Hadassah-Hebrew University Medical Center, Jerusalem, (G.B., G.K., M.M.C.); \\ Department of Pediatrics, Nasr Childrens' Hospital, Gaza (E.E.L., M.El M.); Department of Anatomy and \\ Embryology, Hadassah-Hebrew University Medical Center, Jerusalem, (A.O., E.S.); and Department of Genetics, Tel- \\ Aviv University Medical Center, Rokach Hospital, Tel-Aviv, Israel (C.L.)
}

\begin{abstract}
Summary
A partial deficiency of $\alpha$-mannosidase was found in cultured skin fibroblasts, serum, and extracts of leukocytes in two siblings with mild mental retardation, delayed speech, a suggestion of coarse or full facies, and limited mobility of the large joints. All other lysosomal enzymes tested were within the normal range. Their father demonstrated intermediate $\alpha$-mannosidase activity. The addition of $2 \mathrm{mM} \mathrm{Zn}^{++}$caused a $40 \%$ increase of the $\alpha$ mannosidase activity in cell extracts of both patients and control subjects. pH profiles and Cellogel electrophoresis of the patients' cells indicated $20 \%$ residual activity of the acidic $\alpha$-mannosidase isoenzyme ( $\mathrm{pH}$ optimum at 4.0 ), whereas the activity of the isozyme with $\mathrm{pH}$ optimum of 6.0 was normal. Increasing substrate concentration (1-10 $\mathrm{mM})$ demonstrated a 4to 5-fold increase in the apparent $K_{m}$ of the acidic $\alpha$-mannosidase in the patients' fibroblasts. This residual activity, however, was apparently not sufficient for the normal catabolism of mannose-containing molecules, since electron microscopic examination of the cultured fibroblasts demonstrated numerous lysosomal storage bodies.
\end{abstract}

\section{Speculation}

This family supports the concept that mannosidosis is not a homogeneous syndrome but manifests clinical as well as biochemical heterogeneity. The partial activity of acidic $\alpha$-mannosidase observed in the cultured fibroblasts (approximately 20\%) was insufficient for normal catabolism and allows accumulation of $\alpha$ mannoside-containing substrates leading to the abnormal phenc;type. Nevertheless, this deduction is based on in vitro studies using a synthetic substrate. The observation that $\mathrm{Zn}^{++}$causes a $\mathbf{4 0} \%$ stimulation of acidic $\alpha$-mannosidase activity in the patients' cells agrees with previous findings and may be of significance in the treatment of such cases.

Mannosidosis, a deficiency of the acidic form of $\alpha$-mannosidase (EC 3.3.1.24) $(14,15)$, results in the accumulation of mannose-rich glycosylated compounds in the lysosomes of various tissues $(1,12$, 15) and the excretion of similar compounds in the urine $(13,17$, 18). Clinically, the disorder presents with mildly coarse facies, mild hepatosplenomegaly, skeletal changes, and psychomotor retardation. Human $\alpha$-mannosidase is separable into two distinct isoenzymes in fibroblasts (16) and three distinct isoenzymes in liver (7). In the liver, two isoenzymes, supposedly lysosomal, have acidic optimal activity ( $\mathrm{pH} 4.0-4.5$ ), whereas the third, a nonlysosomal component, is optimally active at $\mathrm{pH} 6.0$ (7). Patients with mannosidosis demonstrate either a complete deficiency or reduced activity of the acidic isoenzymes. Structural changes in the acidic isoenzyme demonstrate a 25 - to 50 -fold increase in apparent $\mathrm{K}_{\mathrm{m}}$ values and high susceptibility to heat inactivation
(4, 6, 8), whereas neutral $\alpha$-mannosidase is normal $(7,11)$. The normal neutral $\alpha$-mannosidase activity may explain the differing residual enzyme activities in various tissues of these patients. We wish to describe a family whose clinical and biochemical findings suggest a new variant of mannosidosis and in which the patients demonstrate only a partial deficiency of the acidic component(s) of $\alpha$-mannosidase with only 4 - to 5-fold increased $\mathrm{K}_{\mathrm{m}}$ values.

\section{CASE REPORT}

A brother (NAS) and sister (BAS), born of a consanguineous mating (Fig. 1; V-7 and V-8), were brought to the Nasr Children's Hospital, Gaza, because of mild mental retardation and delayed speech. The children, who phenotypically were strikingly similar (Figs. 2 and 3), did not resemble their other normal siblings. Family history revealed that four siblings died in infancy: three of pneumonia and one of undetermined cause. In addition, there were two spontaneous abortions.

$$
\text { N.A.S. }
$$

Pregnancy and delivery were normal, but birthweight was unavailable. The patient sat about 1 year of age, walked at 1.5 years, and uttered single words after 2 years of age. At 11 years, when first examined, he had a limited vocabulary, spoke in simple sentences only, and did not attend school. Physical examination revealed a passive but cooperative child whose head circumference was $49 \mathrm{~cm}$, height $123 \mathrm{~cm}$, and weight $25 \mathrm{~kg}$. He had an unusually shaped head with frontal bossing and pronounced supraorbital ridges. His facies was minimally coarse and a squint and conjunctival telangiectasia were noted. Corneal opacities were not observed. The neck was short and he had a pigeon chest. No cardiac murmur was heard; the abdomen was soft; spleen and liver were not enlarged. There were no hernias and the external genitalia appeared normal. Neither kyphosis nor scoliosis were observed but he held himself unusually stiff and straight and lacked the normal spinal curvature. A marked limitation in the range of motion of the large joints, i.e., shoulder, elbow, and knees, was obvious. His hands appeared normal. Hearing was not formally tested but seemed grossly normal.

Peripheral blood smears at first appeared normal but repeated examinations revealed vacuolated lymphocytes (19). Urine spot test was negative for mucopolysaccharides. A skeletal x-ray survey was compatible with dysostosis multiplex and revealed a deformity of the first lumbar vertebral body and a lack of pneumatization of the mastoids.

$$
\text { B.A.S. }
$$

The clinical history and findings of this 5-year-old girl are similar, although not identical, to those of her brother. She is said 

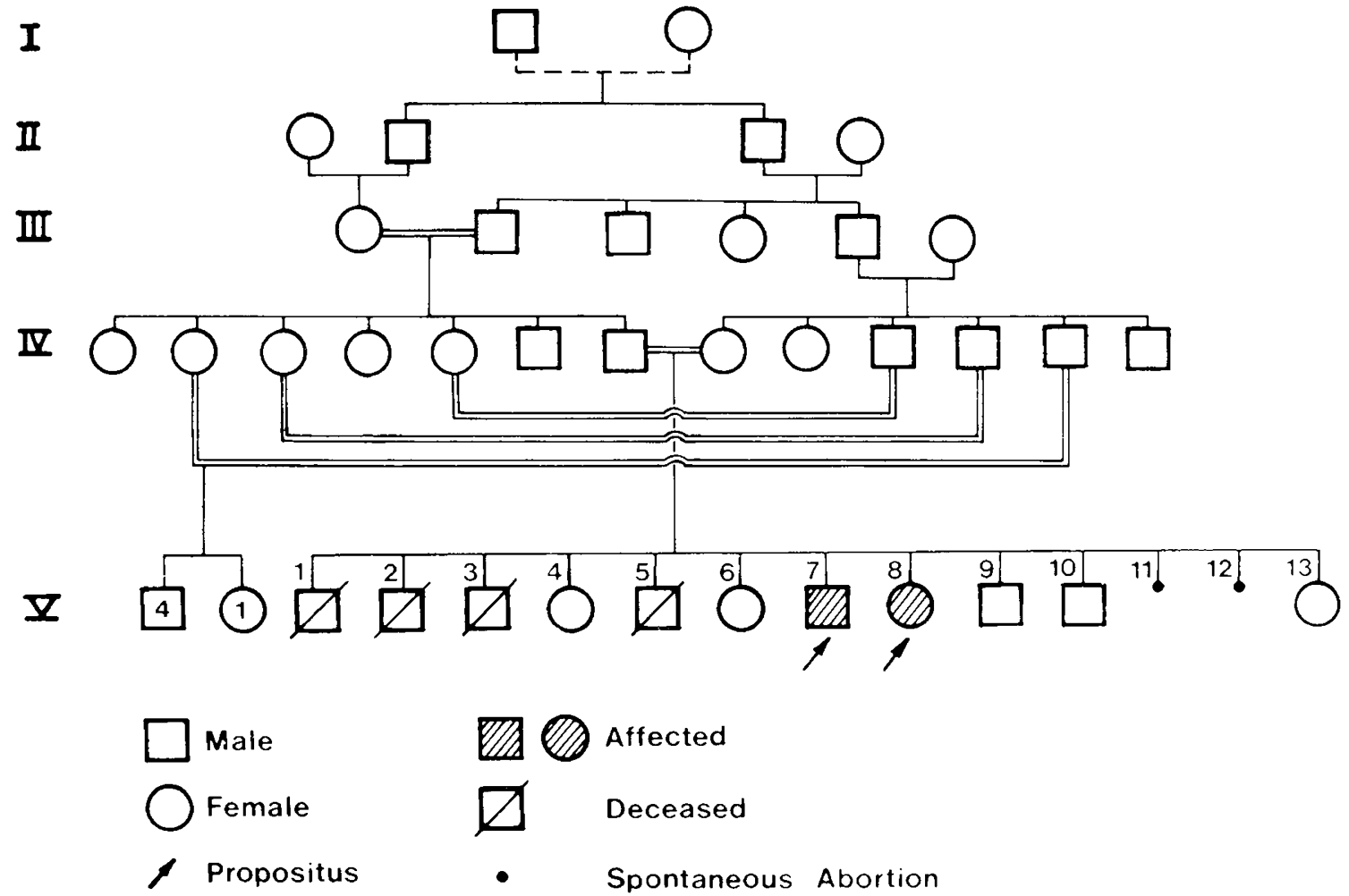

- Spontaneous Abortion

Fig. 1. A pedigree of the family. Note the consanguineous relationship of the parents of the proposita.

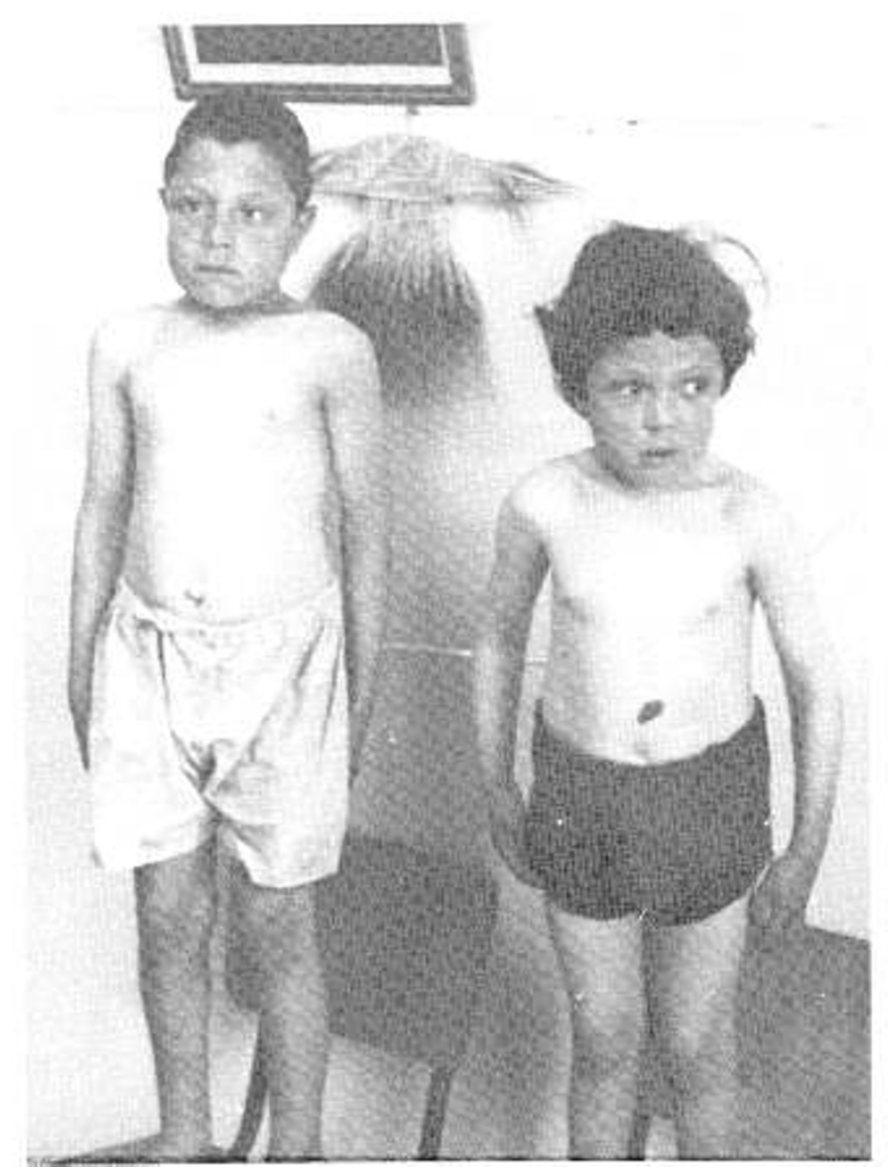

Fig. 2. Patients NAS and BAS at ages 5 and 11 years.

to be irritable. Her vocabulary is limited to only a few single words. Head circumference was $48 \mathrm{~cm}$. She shows frontal bossing, prominent supraorbital ridges, short neck, and limited range of motion at the shoulder elbow and knee joints. She has a II/VI
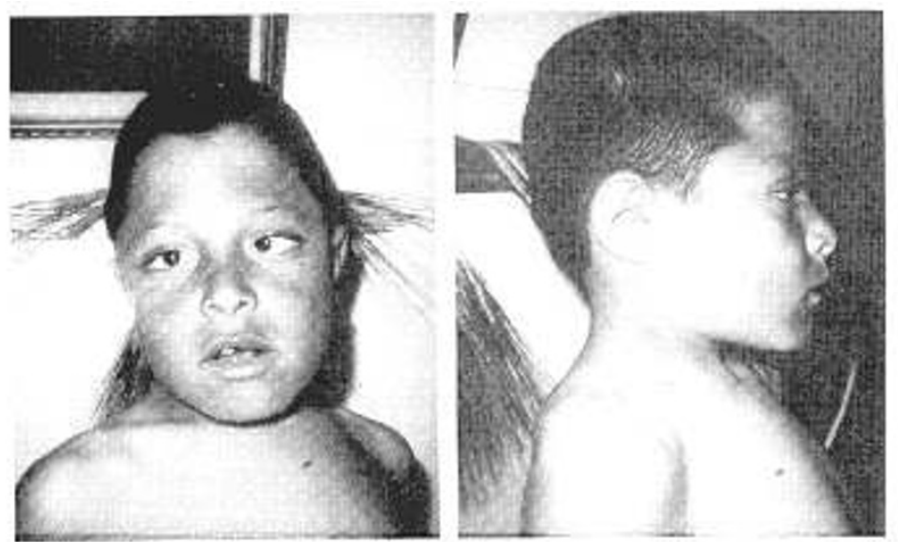

Fig. 3. Full face and profile of patient NAS. Note strabismus.

systolic murmur. There is no organomegaly. Ophthalmologic examination revealed mild bilateral corneal opacities. Hearing was grossly normal. Peripheral blood smear and urinary spot test were normal. Roentgenograms revealed a deformity of the second lumbar vertebral body.

\section{MATERIALS AND METHODS}

Cultured skin fibroblasts obtained from both propositi, their father, and normal control subjects were maintained and propagated as previously described (3). The cells were grown in nutrient mixture F-10 (HAM, Gibco, Grand Island, N. Y.) supplemented with $20 \%$ fetal calf serum in $25 \mathrm{~cm}^{2}$ Falcon flasks in an atmosphere of $95 \%$ air and $5 \% \mathrm{CO}_{2}$. Five to 10 days after passage, cells were harvested by trypsinization and washed twice with $0.9 \% \mathrm{NaCl}$. For enzyme analysis the cells were suspended in $0.5 \mathrm{ml} 0.9 \% \mathrm{NaCl}$ and for electrophoretic studies in $0.5 \mathrm{ml}$ distilled water. Cells were disrupted by five cycles of rapid freezing and thawing and the insoluble material removed by centrifugation at $3^{\circ}$ for $10 \mathrm{~min}$ at $5000 \times g$.

Leukocytes were prepared from $10 \mathrm{ml}$ freshly drawn blood which was mixed with $2 \mathrm{ml}$ of a dextran heparin solution $(5 \mathrm{~g}$ 
Table 1. Acid hydrolase activity (nanomoles per $m g$ protein (per hr) in cultured skin fibroblasts

\begin{tabular}{lcccccc}
\hline & $\beta$-Hexosaminidase & $\beta$-Glucuronidase & $\alpha$-Fucosidase & $\beta$-Galactosidase & Arylsulfatase A $\alpha$-Mannosidase \\
\hline Control $(n=10)$ & $2200-8000$ & $110-190$ & $40-95$ & $300-850$ & $700-1900$ & $40-80$ \\
Mean & 5000 & 130 & 55.0 & 670 & 1200 & $55,77^{2}$ \\
Patient (B.A.S.) & 4673 & 111 & 56.1 & 783 & 1507 & 13.5 \\
& & & & 615 & 1400 & $18.9^{2}$ \\
Patient (N.A.S.) & 5100 & 120 & 41 & 425 & 1209 & 25.3 \\
Father (A.A.S.) & 2900 & 131 & 47 &
\end{tabular}

${ }^{1}$ The activity of $\alpha$-mannosidase was determined as described in the text, using $2 \mathrm{mM} 4$-methylumbelliferyl- $\alpha$-D-mannoside as substrate, dissolved in $0.1 \mathrm{M}$ citrate-phosphate buffer, $\mathrm{pH}$ 4.0.

${ }^{2} \alpha$-Mannosidase activity in the presence of $2 \mathrm{mM} \mathrm{ZnSO}_{4}$. There is a $40 \%$ increase of activity in both normal controls and patient B.A.S

Table 2. $\alpha$-Mannosidase activity of serum and leukocytes

\begin{tabular}{lcc}
\hline & Leukocytes $^{1}$ & Serum $^{2}$ \\
\hline Patient (B.A.S.) & 5.8 & 8.6 \\
Patient (N.A.S.) & 3.7 & 7.6 \\
Father (A.A.S.) & 77.0 & 11.0 \\
Control $(n=10)$ & $96-110$ & $14.2-21.0$ \\
\hline
\end{tabular}

${ }^{1}$ Activity expressed as nmole substrate released per mg protein per $\mathrm{hr}$.

${ }^{2}$ Activity expressed as nmole substrate released per $\mathrm{ml}$ serum per hr.

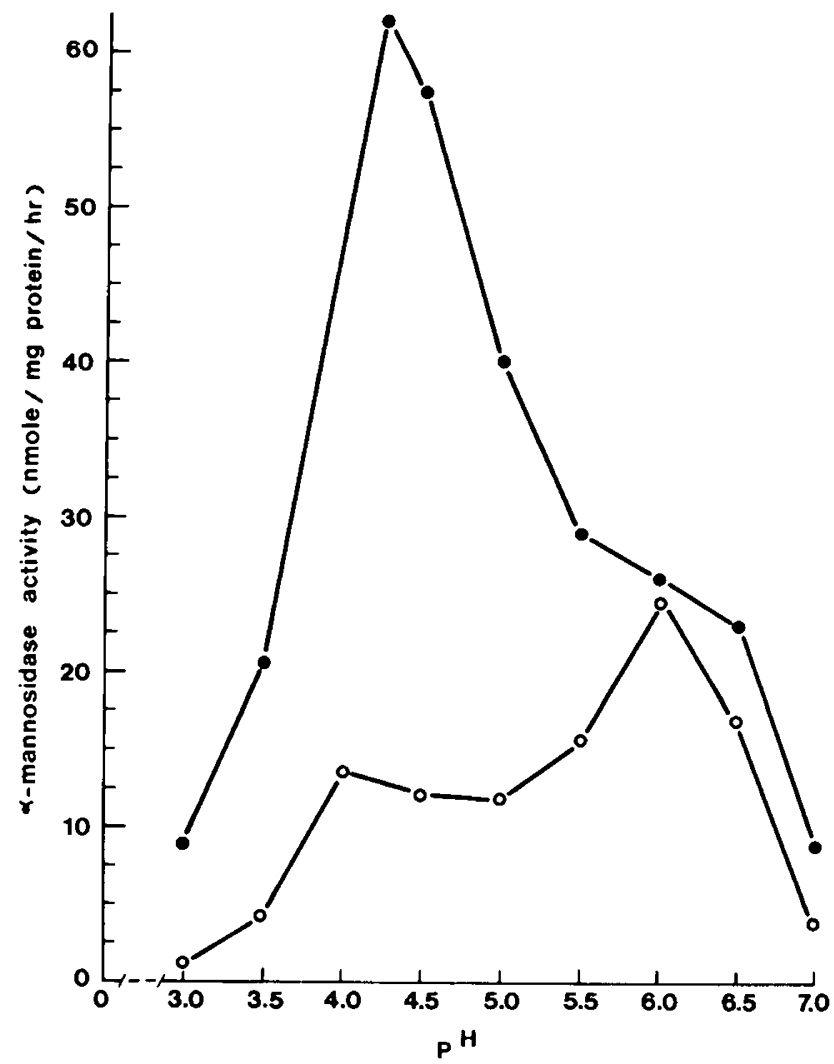

Fig. 4. $\mathrm{pH}$ dependence of $\alpha$-mannosidase activity in citrate phosphate buffer. Assay conditions as described in the text. - normal control fibroblasts; $\bigcirc-O$ : mannosidosis patient (BAS).

dextran, $40 \mathrm{mg}$ heparin, and $0.7 \mathrm{~g} \mathrm{NaCl}$ in $100 \mathrm{ml} \mathrm{H}_{2} \mathrm{O}$ ). The red blood cells were sedimented for $1 \mathrm{hr}$ at $25^{\circ}$ and the leukocytes were isolated from the plasma by centrifugation at $3000 \times g$ for $10 \mathrm{~min}$. The pellet was washed once with $0.9 \% \mathrm{NaCl}$. The remaining red blood cells were lysed in $0.24 \% \mathrm{NaCl}$ and leukocytes were subjected to five cycles of rapid freezing and thawing as described for the fibroblasts.

\section{ENZYME ASSAY}

Activities of $\beta$-hexosaminidase, $\beta$-galactosidase, $\alpha$-mannosidase, $\alpha$-fucosidase, and $\beta$-glucuronidase were determined using 4-

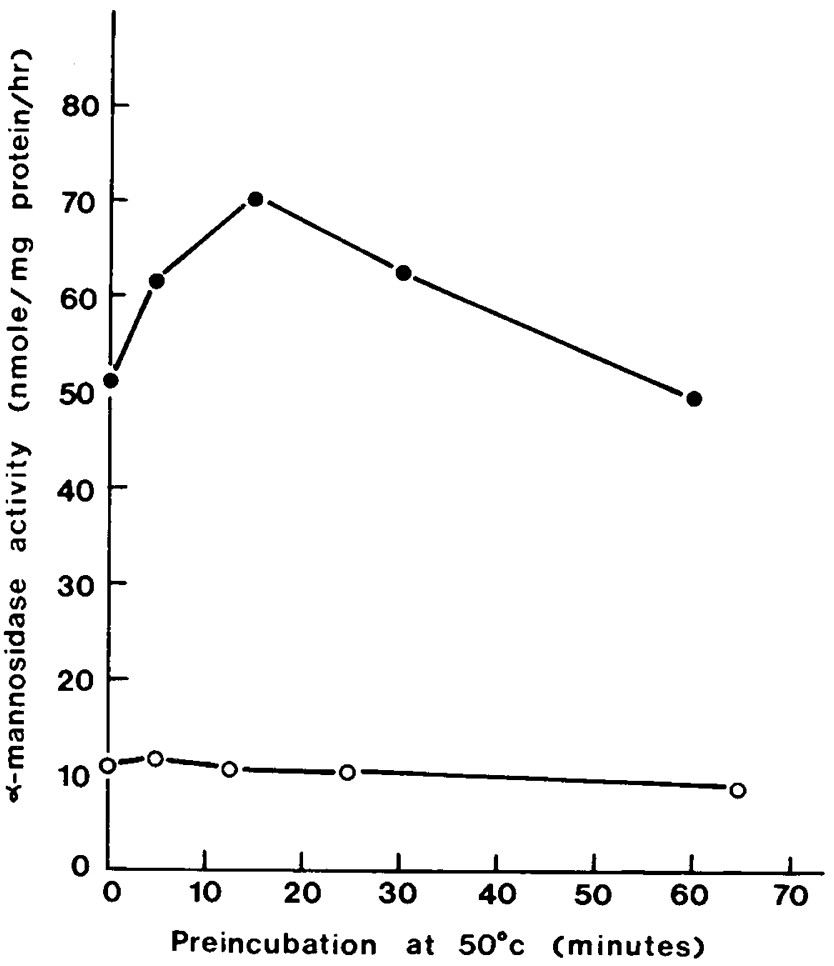

Fig. 5. Stability of acidic $\alpha$-mannosidase after preincubation at $50^{\circ}$ in $0.1 \mathrm{M}$ citrate phosphate $\mathrm{pH}$ 4.0. - - normal control subject; $\mathrm{O} O$ : mannosidosis patient (BAS).

methylumbelliferyl derivatives and of aryl sulfatase A using pnitrocatechol sulfate (Koch Light Co., England). The conditions for the assay of the acid hydrolases have been described in detail elsewhere (5).

\section{HEAT INACTIVATION}

Cell extracts were preincubated in $0.1 \mathrm{M}$ citrate phosphate $(\mathrm{pH}$ 4.0) at $50^{\circ}$ for various time intervals up to $\mathrm{l} \mathrm{hr}$, followed by enzyme assay at $\mathrm{pH} 4.0$.

\section{ELECTROPHORESIS}

Cellogel strips $(5.7 \times 14 \mathrm{~cm}, 0.5 \mathrm{~mm}$ thickness, Chemitron, Milan, Italy), were used to separate the various forms of $\alpha$ mannosidase. Fibroblast extracts, containing $20 \mu \mathrm{g}$ protein, were applied on duplicate gels for each sample at the cathodal end and electrophoresis was performed in $0.035 \mathrm{M}$ sodium citrate buffer at $\mathrm{pH} 6.5,5 \mathrm{~mA} / \mathrm{gel}$ (constant current) for $1 \mathrm{hr}$ at room temperature (16). After electrophoresis, the gels were dipped in $2 \mathrm{mM} \mathrm{4-}$ methylumbelliferyl- $\alpha$-D-mannoside in $0.1 \mathrm{M}$ citrate phosphate buffer, one at $\mathrm{pH} 4.0$ and the other at $\mathrm{pH} 6.0$. The strips were incubated in a sealed container for $30 \mathrm{~min}$ at $37^{\circ}$ and then dipped

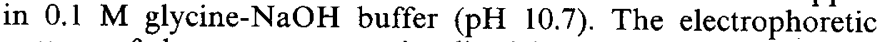
pattern of the enzyme was visualized immediately with a short 
wave ultraviolet lamp (254 mm, Ultraviolet Cabinet, model cc20, Arthur Thomas Co.) and photographed.

\section{ULTRASTRUCTURAL STUDIES}

Cultured skin fibroblasts were harvested by trypsinization, washed twice with $0.9 \% \mathrm{NaCl}$, centrifuged, and fixed in a mixture of $0.67 \%$ glutaraldehyde and $1.5 \%$ osmic acid with cacodylate buffer $0.1 \mathrm{M}$ ( $\mathrm{pH} 7.2$ ). After routine dehydration, embedding and polymerization, the specimens were sectioned with a Sorvall Porter-Blum MT2-B ultramicrotome. Thin sections were stained by

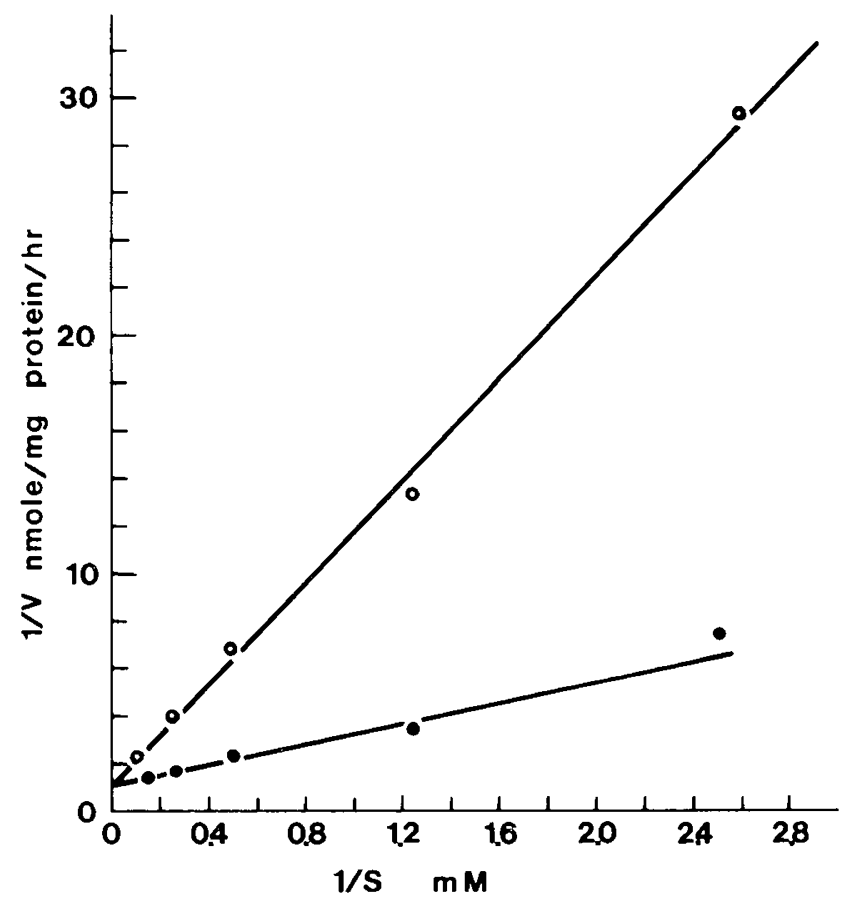

Fig. 6. Michaelis-Menten plot of acidic $\alpha$-mannosidase activity in fibroblast extracts. Enzyme activity was determined in citrate phosphate buffer pH 4.0. $\longrightarrow$ : normal control subject; $\bigcirc-0$ : mannosidosis patient (BAS) uranyl acetate and lead citrate and examined with a Phillips 300 electron microscope.

\section{RESULTS}

Among the acid hydrolases tested, $\alpha$-mannosidase was the only lysosomal enzyme in cultured fibroblasts of the two patients which demonstrated significantly reduced activity (Table 1). In both patients, $\alpha$-mannosidase activity was $15-20 \%$ of normal control values whereas their father showed intermediate activity ( $45 \%$ of normal), indicative of a heterozygote and clearly demonstrating that mannosidosis is present in this family. Such residual enzyme activity in our patients was somewhat higher than that usually found in most mannosidosis patients reported previously. Mixing equal aliquots of fibroblast extracts from the patients and normal control subjects yielded the expected intermediate values, thereby ruling out the presence of an inhibitor in the patients' cells. The addition of $2 \mathrm{mM} \mathrm{ZnSO}_{4}$ (Table 1) caused approximately a $40 \%$ stimulation of the $\alpha$-mannosidase activity in both affected and normal cells. The residual activity in leukocyte extracts (Table 2) of the two patients was lower than $10 \%$ of the normal values, but the enzyme activity in serum was approximately $50 \%$ of the controls. Enzyme activity of the father was distinctly lower than all the controls tested, regardless of tissue source.

Additional biochemical differences in the cultured fibroblasts of our patients suggest a variant of mannosidosis. The $\mathrm{pH}$ profile of the enzyme demonstrates a distinct, although decreased, activity peak at $\mathrm{pH} 4.0$ (Fig. 4). This $\mathrm{pH}$ represents the major activity peak in the controls. The patients' "neutral" $\alpha$-mannosidase, with maximal activity at $\mathrm{pH} 6.0$, showed activity similar to that of the normal control subjects.

After $1 \mathrm{hr}$ of preincubation at $50^{\circ}$, only minor differences in the thermostability of the acidic mannosidase isoenzymes in our patient and the control subjects were noted (Fig. 5). Figure 6 shows a distinct 4- to 5-fold increase of the acidic $\alpha$-mannosidase apparent $\mathrm{K}_{\mathrm{m}}$ values of patient B.A.S.'s $\left(\mathrm{K}_{\mathrm{m}}=2.2 \mathrm{mM}\right.$ in controls vs. $10.25 \mathrm{mM}$ in the patients), whereas the intercept with the ordinate was identical in both enzyme preparations. At substrate concentrations higher than $10 \mathrm{mM}$, the enzymatic activity in our patients approached that of the controls.

After electrophoresis, the isozyme patterns clearly indicate residual activity at $\mathrm{pH} 4.0$ in the patients, with mobility identical to that found in normal subjects (Fig. 7). The pattern of the neutral
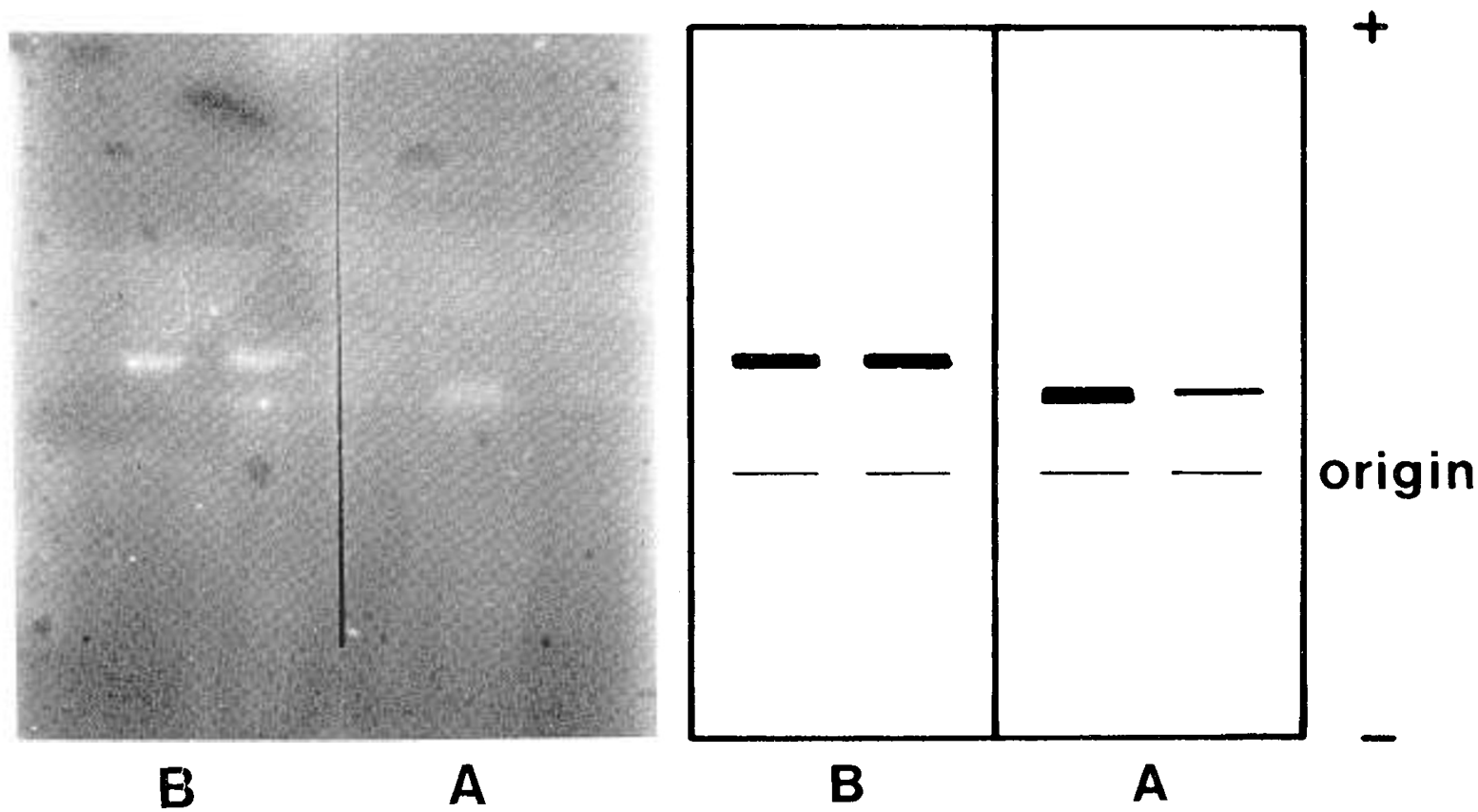

Fig. 7. Electrophoretic pattern of $\alpha$-mannosidase of cultured fibroblast extracts. $A$ : incubation of the gel with substrate at pH 4.0 ; $B$ : incubation of the gel with substrate at $\mathrm{pH}$ 6.0. Control subject on left of each panel; mannosidosis patient (BAS) on right. 


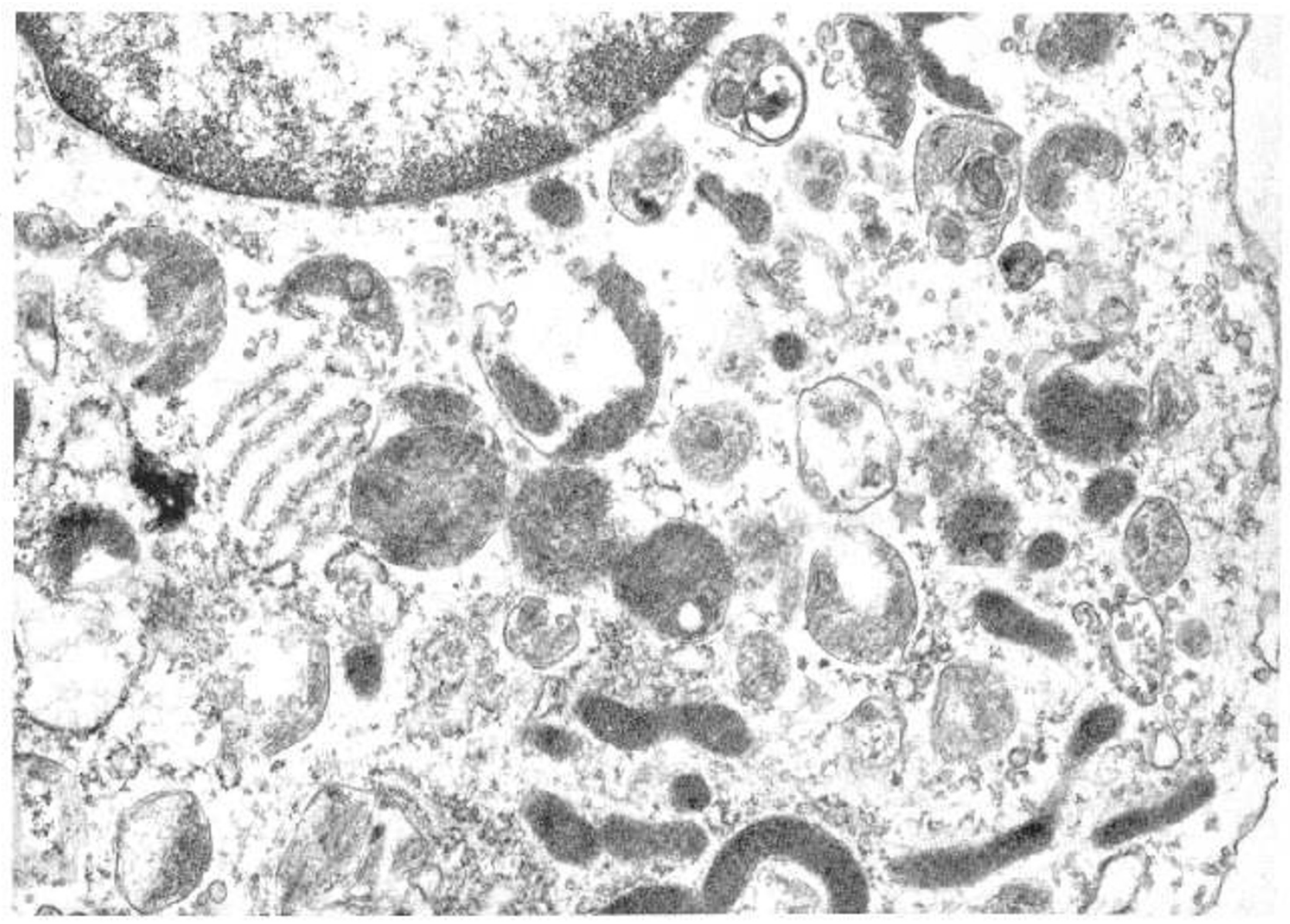

Fig. 8. Ultrastructure of cultured fibroblast from mannosidosis patient (BAS) $(25,000 \times)$. Note the numerous abnormal storage organelles surrounded by single membrane (arrows).

mannosidase component showed no apparent differences in the two extracts.

In the cultured fibroblasts of both patients, numerous single membrane cytoplasmic inclusions, containing typical granular and amorphous storage material, were observed. Some of these inclusions showed lamellar configuration, whereas others were half empty or contained only remnants of granular material adherent to the inner aspect of the membrane (Fig. 8). About $50 \%$ of the fibroblasts of N.A.S. showed multiple inclusions per cell (more than five in each cell section); whereas in B.A.S., more than $90 \%$ of the cells were severely affected.

\section{DISCUSSION}

Since the initial description of mannosidosis in 1967 (14), the biochemistry of this disorder has been characterized in several laboratories $(1-3,9-17)$. Heterogeneity has been observed in both the clinical severity and the biochemistry of this entity. Residual $\alpha$-mannosidase activity of the total homogenate at $\mathrm{pH} 4.0-4.5$ varies among tissues $(1,11,14)$; enzyme activity from cultured skin fibroblasts, obtained from various patients, did not exceed $10 \%$ of normal values when measured at substrate concentrations of up to $2 \mathrm{mM}(2,4,6,8,9,16)$. Recently, increased residual activity in cultured skin fibroblasts, serum, and leukocytes, similar to that observed in our patients, has been reported (10). However, the lack of a detailed study of the residual activity in that report does not allow detailed comparison of the cases. Residual enzyme activity in earlier reports was initially attributed to the neutral $\alpha$ mannosidase component since both $\mathrm{pH}$ studies and electrophoretic patterns showed completely deficient activity at $\mathrm{pH} 4.0$, whereas the activity at $\mathrm{pH} 6.0$ was normal $(2,7,9,16)$. However, in some patients, recent studies suggest the existence of residual acidic mannosidase activity which is heat labile and demonstrates a greater than 25 -fold increase in $\mathrm{K}_{\mathrm{m}}$ values $(4,6,8)$. In contrast to these cases, our patients demonstrate a different mutation controlling the acidic component of $\alpha$-mannosidase. The residual activity of the enzyme, assayed in cultured fibroblasts with the synthetic substrate in concentrations of up to $2 \mathrm{mM}$, was significantly higher (15-20\% of normal subjects), although still lower and clearly distinguishable from control or heterozygote subjects.

Enzymatic activity of the acidic component is clearly demonstrated by both pH studies (Fig. 4) and the electrophoretic patterns (Fig. 7). In other cases, however, residual acidic activity was detected by electrophoresis only when using much higher protein concentrations (17). These results, plus the 4- to 5-fold increase of the apparent $\mathrm{K}_{\mathrm{m}}$, suggest a mutation of the $\alpha$-mannosidase gene yielding a defective protein with different in vitro properties than previously reported. Although the mutant enzyme was heat stable, similar to that reported by Beaudet and Nichols (4), its stimulation by $\mathrm{ZnSO}_{4}$, similar to the response of controls, plus the observation that its increase in apparent $K_{m}$ was much lower than that previously reported $(4,8)$, clearly distinguishes it from other cases. The acidic component of $\alpha$-mannosidase in our patients was easily detected with the same protein concentrations used in control subjects, indicating a greater residual activity than in the patients described by either Booth et al. (6) or Desnick et al. (8). These in vitro studies, although performed with the synthetic substrates using crude cells extracts, suggest that the mutant enzyme might require higher than normal substrate concentrations for the hydrolysis of mannoside containing molecules, leading to their accumulation. Such partial accumulation may lead to a similar, although milder clinical picture, than that found in patients with no acidic activity whatsoever. The present cases demonstrated only mild mental retardation and relatively minor skeletal changes. Mild clinical manifestations have already been described 
in a patient with residual acidic $\alpha$-mannosidase activity demonstrated electrophoretically (6).

Although the leukocyte residual activity was lower than that found in cultured skin fibroblasts, it was still higher than that in other patients (8). Nevertheless, numerous storage organelles in cultured skin fibroblasts (Fig. 8) and vacuolated leukocytes indicate that even the increased residual activity in this tissue was insufficient for the normal catabolism of mannoside-containing substrates.

\section{CONCLUSION}

This family represents yet another example of the documented genetic heterogeneity in mannosidosis $(1,2,6)$. The patients described are the products of a consanguineous Arab mating and demonstrate a mild clinical variant of mannosidosis. Biochemically, they show higher residual acidic $\alpha$-mannosidase activity ( $\mathrm{pH}$ optimum 4.0) than most patients hitherto reported. The great heterogeneity observed in mannosidosis emphasizes the necessity of careful biochemical investigations of this disorder. For instance, in the present case, the residual activity of $\alpha$-mannosidase becomes less distinguishable from normal when higher substrate concentrations $(>10 \mathrm{mM})$ are used, because of a 4- to 5-fold increase in apparent $\mathrm{K}_{\mathrm{m}}$. As already pointed out by Beaudet and Nichols (4), this observation raises the possibility of misdiagnosis if substrate concentrations are not carefully controlled.

\section{REFERENCES AND NOTES}

1. Autio, S., Norden, N. E., Ockerman, P. A., Riekkinen, P., Rapola, J. and Louhimo, T.: Mannosidosis: Clinical, fine structural and biochemical findings in three cases. Acta Pediat. Scand., 62: 555 (1973).

2. Aylsworth, A., Taylor, H. A., and Stuart, C. M.: Mannosidosis: Phenotype of a severely affected child and characterization of $\alpha$-mannosidase activity in cultured fibroblasts from the patient and his parents. J. Pediat., 88: 814 (1976).

3. Bach, G., Cohen, M. M., and Kohn, G.: Abnormal ganglioside accumulation in cultured fibroblasts from patients with mucolipidosis IV. Biochem. Biophys. Res. Commun., 64: 1483 (1975).

4. Beaudet, A. L., and Nichols, B. L.: Residual altered $\alpha$-mannosidase in human mannosidosis. Biochem. Biophys. Res. Commun., 68: 292 (1976).

5. Berman, E. R., Livni, N., Shapira, E., Merin, S., and Levij, I. S.: Congenital corneal clouding with abnormal storage bodies: A new variant of mucolipidosis. J. Pediat., 84: 519 (1974).

6. Booth, C. W., Chen, K. K., and Nadler, H. L.: Mannosidosis: Clinical and biochemical studies in a family of affected adolescents and adults. J. Pediat., 88: 821 (1976)

7. Carrol, N., Dance, N., Masson, P. K., Robinson, D., and Winchester, B. G. Human mannosidosis - the enzyme defect. Biochem. Biophys. Res. Commun., 49: 579 (1972)

8. Desnick, R. J., Sharp, H. L., Grabowski, G. A., Brunning, R. D., Quie, P. G., Sung, J. H., Gorlin, R. J., and Ikonne, J. U.: Mannosidosis: Clinical, morphologic, immunologic and biochemical studies. Pediat. Res., 10: 985 (1976).

9. Gehler, J., Cantz, M., O'Brien, J. E., Tolksdorf, M., and Spranger, J.: “Mannosidosis" clinical and biochemical findings. in: D. Bergsma: Disorders of Connective Tissue, pp. 269-272 (Stratton Intercontinental Medical Book Co., 1975).

10. Kistler, J. P., Lott, I. T., Kolodny, E. H., Friedman, R. B., Nerasian, R., Schnur, J., Mihm, M. C., Dvorak, A. M., and Dickersin, R.: Mannosidosis. Arch. Neurol., 34: 45-51 (1977).

11. Masson, P. K, and Lundblad, A.: Mannosidosis: Detection of the disease and of heterozygotes using serum and leukocytes. Biochem. Biophys. Res. Commun., 56: 296 (1974)

12. Mersmann, G., von Figura, K., and Buddecke, E.: Storage of mannose-containing material in cultured human mannosidosis cells and metabolic correction by pig kidney $\alpha$-mannosidase. Hoppe-Seyler's Z. Physiol. Chem., 357: 641 (1976).

13. Norden, N. E., Lundblad A., Svensson, S., Ockerman, P. A., and Autio, S.: A mannose-containing trisaccharide isolated from urines of three patients with mannosidosis. J. Biol. Chem., 248: 6210 (1973).

14. Ockerman, P. A.: A generalized disorder resembling Hurler's syndrome. Lancet, ii: 329 (1967).

15. Ockerman, P. A.: Mannosidosis. In: J. G. Hers and F. Van Hoof: Lysosomes and Storage Diseases, pp. 291-304, (Academic Press, New York, 1973).

16. Taylor, H. A. Thomas, G. H., Aylsworth, A., Stevenson, R. E., and Reynolds, L. W.: Mannosidosis: Deficiency of a specific $\alpha$-mannosidase component in cultured fibroblasts. Clin. Chim. Acta, 59: 92 (1975).

17. Tsay, G. C., Dawson, G., and Matalon, R.: "Excretion of mannose rich complex carbohydrates by a patient with $\alpha$-mannosidase deficiency. J. Pediat., 84: 865 (1974).

18. Vamos-Hurwitz, E., Tondeur, M., Humbel, R., Philippart, M., Hosli, P., and Loeb, H.: Mannosidosis: Findings in cultured fibroblasts and urine. Acta Paediat. Scand., 64: 865 (1975).

19. Blood smears were kindly reviewed by Dr. Robert J. Desnick, Professor of Pediatrics and Genetics, Mt. Sinai Hospital, New York City and Dr. Richard Brunning, Professor of Laboratory Medicine and Pathology, University of Minnesota Hospital, Minneapolis, MN.

20. Informed consent for these studies was obtained from all the patients and controls whose cells were used. The parents were informed that photographs were taken for possible publication in a medical journal and permission for this was given.

21. M. M. Cohen is an Established Investigator of the Chief Scientist's Bureau, Israel Ministry of Health.

22. This research was supported by grants from the National Foundation-March of Dimes and the Israel Ministry of Health (no. 371).

23. Requests for reprints should be addressed to: Gideon Bach, Ph.D., Department of Human Genetics, Hadassah-Hebrew University Medical Center, Jerusalem (Israel).

24. Received for publication March 15, 1977

25. Accepted for publication January 27, 1978. 